\title{
Applicability and Effectiveness of Closed Reduction of Nasal Fractures under Local Anesthesia
}

\author{
Fernando Vilela ${ }^{1}$ Ronaldo Granjeiro ${ }^{1}$ Carlos Maurício Júnior ${ }^{1}$ Patrícia Andrade ${ }^{1}$ \\ ${ }^{1}$ Department of Otorhinolaryngology, Hospital de Base Brasília, \\ Distrito Federal, Brazil \\ Int Arch Otorhinolaryngol 2014;18:266-271. \\ Address for correspondence Fernando Vilela, MD, Department of \\ Otorrinolaringologia, Marus Clínica, Av Santos Dumont 283, Centro, \\ Uberaba, Minas Gerais, 38010370, Brazil \\ (e-mail: ffvilela@hotmail.com; ffvilela@yahoo.com.br).
}

\begin{abstract}
Introduction A significant portion of patients treated in emergency departments have nasal fracture. It is important that the otolaryngologist know how to treat such damage.

Objectives To evaluate the effectiveness of nasal fracture reduction under local anesthesia and tolerance to the procedure.

Methods Twenty-four patients treated in the emergency department with closed reduction under local anesthesia were prospectively followed. Epidemiologic information and data regarding pain and complications during the management were noted. The degree of satisfaction was researched by visual analog scale.

Results The majority of patients were male (75\%), and the most common cause of injury was motor vehicle accident. We found a significant association between time to reduction and referred pain during the procedure. In patients in whom the procedure was delayed (over 3 days), there was less pain, and those who bled during the procedure

Keywords

- traumatology

- nasal bone

- nose deformities

- acquired had a shorter average time to reduction than the group of patients who did not bleed. Most patients were very satisfied, with more than $95 \%$ of these willing to undergo the same process again, if necessary.

Conclusions The closed approach in the clinic under local anesthesia was effective and safe in restoration of the nose.
\end{abstract}

\section{Introduction}

Due to its prominent position on the face, the nose is very susceptible to trauma and fractures, and $39 \%$ of all facial fractures are nasal fracture. ${ }^{1,2}$ Fracture is suspected in the presence of external deformity, palpation of fragments, bones instability, and crackling. Often signs of epistaxis, nasal swelling, nasal obstruction symptoms, and local pain are also present.

The purpose of manipulation of nasal fractures is aestheticfunctional correction of the nose, with a view to cosmetic and functional results. The surgical treatment varies significantly, including technical aspects and the type of anesthesia employed. Some services recommend nasal fracture reduction under general anesthesia, although local anesthesia is used for treatment of these diseases on a large scale, due mainly to the technical ease and good results. ${ }^{3,4}$ With local anesthesia, administration through the outer skin of the nasal dorsum was described as best to control pain when compared with intranasal infiltration, both associated with intranasal cocaine solution. ${ }^{5}$ However, there are good results with other anesthetic techniques, such as topical tetracaine gel, also in association with intranasal solution cocaine. ${ }^{6}$

Nasal fractures can be manipulated through the "closed" or "open" surgical procedure with open formal incisions and received

October 31, 2013

accepted

November 16, 2013

published online

March 13, 2014
DOI http://dx.doi.org/

10.1055/s-0034-1368138. ISSN 1809-9777.
Copyright $\odot 2014$ by Thieme Publicações License terms Ltda, Rio de Janeiro, Brazil

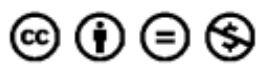


management of nasal bones and septum as in the conventional rhinoseptoplasties. The closed path is indicated in cases of unilateral and bilateral fractures with deviation less than half the depth of the nasal tip. ${ }^{7}$ The open approach is usually reserved for cases of residual cosmetic deformity and complex or comminuted fractures. If necessary (for example, due to emotional changes, young age, severe pain intolerance, or allergies to certain anesthetic medications), the procedure can be performed under general anesthesia. Murray and Maran, in a prospective study of 756 patients treated by closed reduction, found that $59 \%$ had no residual nasal deformity. ${ }^{8}$ However, Rajapakse et al fared better, averaging functional and aesthetic satisfaction in 86 and $84 \%$ of patients after closed reduction with both general and local anesthesia, respectively. They concluded that from the point of view of the patient, both types of anesthesia are acceptable. In this study, $69 \%$ of patients would accept a new approach under local anesthesia. ${ }^{9}$ Waldron et al found acceptance of this type of anesthesia in $92 \%$ of patients. ${ }^{10}$

Nasal fractures are a common problem in the emergency room, especially in units of otolaryngology and plastic surgery. Detailed knowledge of the epidemiology and diagnostic and therapeutic methods becomes imperative for the effectiveness of patient care. Studies on the topic have been conducted frequently in recent years but have noted a controversy as to the management of fractures, highlighting the need to carry out additional work.

This study is a survey of epidemiologic data to evaluate the effectiveness of the reduction of nasal fractures under local anesthesia and complications during the procedure in patients treated in the emergency room of otolaryngology services.

\section{Methods}

The study was conducted from May 2010 to September 2011 in a tertiary hospital in Brazil, with patients signing consent forms, after approval by the Institutional Ethics Committee (protocol no. 556/11). The study was designed as a longitudinal cohort study. We prospectively evaluated 24 patients with nasal fractures treated at the emergency department in a tertiary hospital. Inclusion criteria were isolated nasal fractures of duration up to 14 days with acute aesthetic or functional deformity of the nose. Exclusion criteria were patients younger than 12 years with decompensated systemic comorbidities, craniofacial cosmetic deformity from previous nasal trauma, history of adverse reaction to local anesthetics, and clinical instability at query time.

The evaluation consisted of three stages (pre-, intra-, and postprocedure). Fracture diagnosis was based on clinical history, physical examination, and radiography of the nasal bones.

In the first step, we collected epidemiologic data, such as sex, age, race, date and time of injury, date and time of medical care, and causes of the trauma. Then the patients were physically examined by an ear, nose, and throat (ENT) specialist, who described the characteristics of the fractures (deviated noses, sinking back, deviated nasal septum, septal hematoma or abscess, edema, and associated facial fractures).
In the second step, following guidelines of the procedures, nasal fracture reduction was performed in the emergency room of the office under local anesthesia with peripheral venous access. We used $6 \mathrm{~mL}$ of lidocaine $2 \%$ without vasoconstrictor by infiltration exclusively external using a Gelco 22G (Smiths Medical's popular JELCO ${ }^{\circledR}$ ); $1 \mathrm{~mL}$ was injected into the space between the medial canthal and glabellar region on each side to reach the periosteum to provide nasociliary nerve anesthesia, and $2 \mathrm{~mL}$ was injected $1 \mathrm{~cm}$ below the infraorbital rim bilaterally to infraorbital nerve anesthesia. Manual reduction was used combined with intranasal blunt instruments such as anatomical cable clamps. We did not use elevator or forceps. The patient sat with head supported in a chair for ENT examination. External fixation was performed with Micropore ${ }^{\mathrm{TM}}\left(3 \mathrm{M}^{\mathrm{TM}}\right)$ without use of gypsum or rigid materials. Nasal packing was reserved only for cases of bleeding that persisted after the initial measures, including nasal lavage with saline and compression bidigital nose. Nasal splint was not used. We recorded the date of the reduction of the nasal fracture and complications of the procedure, such as bleeding and lipothymia (when there was paleness, cold sweat, dizziness, and feeling faint, although it rarely caused complete loss of consciousness). Pain was assessed using the visual analogue scale (VAS), with values from 0 to 10 (where $0=$ absent pain and $10=$ unbearable pain). Moreover, in the immediate postoperative period, the patients answered if they would or not accept the same procedure under local anesthesia again, if necessary. The procedure was performed by a single physician otolaryngology resident, under the supervision of the advisor.

Finally, the patients were reevaluated in an ambulatory setting $\sim 6$ months after reduction. They were asked about their functional and aesthetic result and nasal assessment by VAS, scoring from 0 (worst) to 10 (excellent) for each item. They were also asked whether they would accept the same treatment again in view of the results obtained. Scores were classified into dissatisfied ( 0 to 5 ), somewhat satisfied (6 to 8), and very satisfied (9 to 10 ).

\section{Statistical Analysis}

The data set was organized in Excel spreadsheets (Microsoft Corp., Redmond, Washington, United States). All analyzes were performed with SPSS (Statistical Package for the Social Sciences, Chicago, Illinois, United States version 13 for Windows (Microsoft). The results are presented as mean \pm standard error of the mean.

Possible associations between qualitative variables were evaluated with the Fisher exact test. The possible correlation between time to reduction and pain was analyzed with the Pearson test. The comparisons of time to reduction between groups of patients were made using the Mann-Whitney test. Grouping was based on the sample characteristics or outcomes, and the methodology is explained in each section. The level of statistical significance was set at $5 \%(p<0.05)$. All tests were two-tailed.

The time to reduction was classified as an ordinal variable of two levels (up to 3 days or more than 3 days). The variables of functional satisfaction and aesthetics satisfaction were 


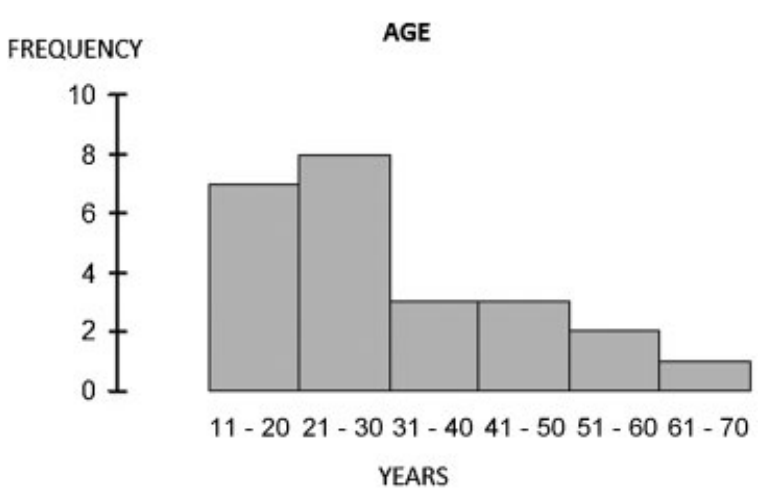

Fig. 1 Histogram of the variable of patient age $(n=24)$.

transformed into two ordinal variables levels (up to 8 or more than 8). The results of the pain scale were transformed into a categorical variable with two levels ( 0 to 4 or 5 to 10 ).

\section{Results}

The mean age of patients was $30.1 \pm 2.9$ years (minimum 12 and maximum 61 years; -Fig. 1). The characteristics are described in $\boldsymbol{-}$ Table 1. Most patients were men of mixed race who presented to the emergency room on Sunday (-Fig. 2). In most patients, the fracture was evident on chest X-ray showing bones of the nose. The causes of fracture were many, the most common related to automobile accidents and violence.

The most common findings on physical examination were deviated noses and nasal septum deviation. Aligned fracture was an uncommon finding (-Table 2 ).

Most patients underwent intervention in the first 3 days after the fracture (-Fig. $\mathbf{3}$ ). The average interval of time between the injury and the reduction was $3.4 \pm 0.6$ days (minimum 0 and up to 13 days). Patients undergoing nasal fracture reduction under local anesthesia showed few complications; half of them had typically ephemeral and small bleeding ( - Table 3 ). Most patients were very satisfied with the results ( - Table 4), with high aesthetic $(8.7 \pm 0.2)$ and functional $(9.0 \pm 0.2)$ satisfaction. Most patients would accept the procedure again, if necessary, and few needed reoperation (-Table 5). There were low levels of pain $(4.8 \pm 0.5)$, with high aesthetic $(8.7 \pm 0.2)$ and functional $(9.0 \pm 0.2)$ satisfaction (-Fig. 4).

\section{Influence of Time to Reduction on Procedure Outcomes}

A statistically significant association between this variable (up to 3 days or more than 3 days until the reduction) and the outcomes of the procedure (bleeding, general malaise, syncope, satisfaction, and reintervention) could not be demonstrated $(p>0.266)$. There was a statistically significant correlation between time to reduction and referred pain during the procedure $(r=-0.598, p=0.003, n=23)$. The longer the time until reduction, the lower the pain score (-Fig. 5).

Despite the lack of association between variables, comparison of the time to reduction (quantitative variable) showed a statistically significant difference between patients who did
Table 1 Distribution of frequencies for the sample variables

\begin{tabular}{|c|c|c|}
\hline Variable & $n$ & $\%$ \\
\hline \multicolumn{3}{|l|}{ Sex } \\
\hline Female & 6 & 25.0 \\
\hline Male & 18 & 75.0 \\
\hline \multicolumn{3}{|l|}{ Race } \\
\hline White & 9 & 37.5 \\
\hline Mixed & 15 & 62.5 \\
\hline \multicolumn{3}{|l|}{ Day of the week } \\
\hline Monday & 3 & 12.5 \\
\hline Tuesday & 1 & 4.2 \\
\hline Wednesday & 4 & 16.7 \\
\hline Thursday & 2 & 8.3 \\
\hline Friday & 1 & 4.2 \\
\hline Saturday & 3 & 12.5 \\
\hline Sunday & 10 & 41.7 \\
\hline \multicolumn{3}{|l|}{ Cause } \\
\hline Aggression & 6 & 25.0 \\
\hline Automobile accident ${ }^{\mathrm{a}}$ & 7 & 29.2 \\
\hline Sport & 5 & 20.8 \\
\hline Fall & 2 & 8.3 \\
\hline Other $^{b}$ & 4 & 16.7 \\
\hline \multicolumn{3}{|l|}{ Fracture on the radiograph } \\
\hline No & 2 & 8.3 \\
\hline Yes & 21 & 87.5 \\
\hline Unrealized & 1 & 4.2 \\
\hline
\end{tabular}

ancluding pedestrians.

${ }^{b}$ Work accident and trauma not associated with fall.

or did not bleed during the procedure (-Fig. 6). Patients who bled had a mean lower score for between traumatic injury and reduction, compared with patients who did not bleed $(2.2 \pm 0.4$ versus $4.7 \pm 1.1$ days, respectively, $p=0.036)$.

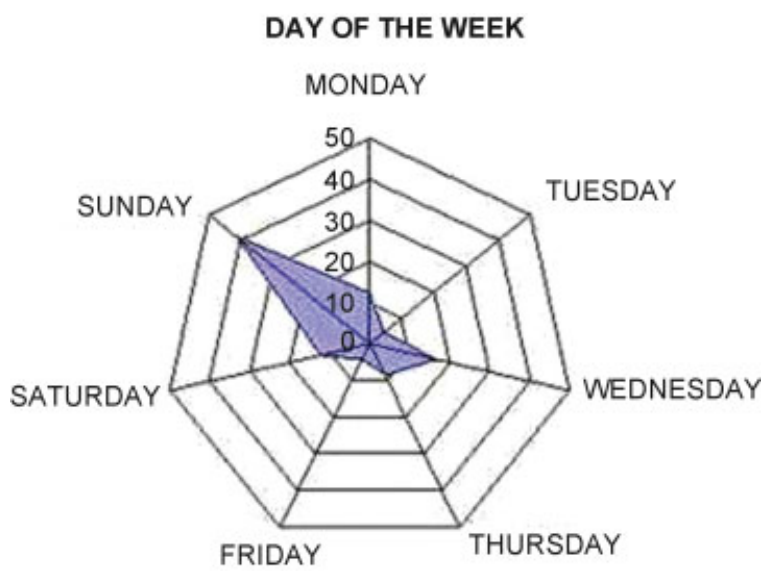

Fig. 2 Frequency distribution (percentage) of the variable of day of the week $(n=24)$. 
Closed Reduction of Nasal Fractures under Local Anesthesia Vilela et al. 269

Table 2 Distribution of frequencies for physical examination findings in the emergency department

\begin{tabular}{|l|l|l|}
\hline Physical examination & $n$ & $\%$ \\
\hline Sinking of the nasal dorsum & 7 & 29.2 \\
\hline Edema & 7 & 29.2 \\
\hline Fracture aligned & 2 & 8.3 \\
\hline Deviated noses & 12 & 50.0 \\
\hline Right & 9 & 37.5 \\
\hline Left & 21 & 87.5 \\
\hline Total & \multicolumn{2}{|l}{} \\
\hline Septal deviation & 8 & 33.3 \\
\hline Right & 4 & 16.7 \\
\hline Left & 12 & 50.0 \\
\hline Total & \multicolumn{2}{|l}{} \\
\hline
\end{tabular}

$$
\begin{gathered}
\text { FREQUENCY } \\
16 \text { - } \\
14- \\
12- \\
10- \\
8- \\
6- \\
4- \\
2- \\
0-
\end{gathered}
$$

TIME FOR REDUCTION

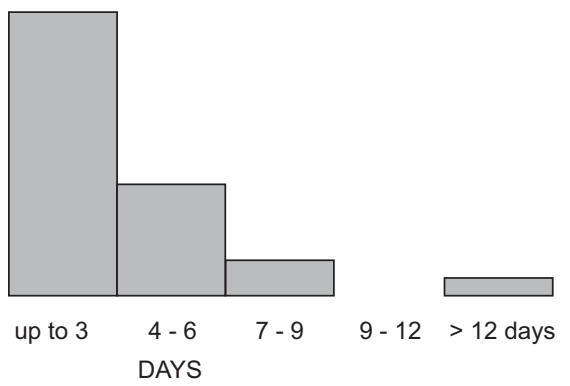

Fig. 3 Histogram of the variable of time for fracture reduction $(n=24)$.

Table 3 Distribution of frequency of procedure complications

\begin{tabular}{|l|l|l|}
\hline Complications & $\boldsymbol{n}$ & $\%$ \\
\hline Bleeding & 12 & 50.0 \\
\hline Malaise & 2 & 8.3 \\
\hline Lipothymia & 3 & 12.5 \\
\hline
\end{tabular}

Table 4 Degree of aesthetic and functional satisfaction after reduction procedure $(n=23)$

\begin{tabular}{|l|l|l|}
\hline Satisfaction & $\begin{array}{l}\text { Aesthetics, } \\
\boldsymbol{n}(\%)\end{array}$ & $\begin{array}{l}\text { Functional, } \\
\boldsymbol{n}(\%)\end{array}$ \\
\hline Satisfied (9-10) & $16(69.56 \%)$ & $18(78.26 \%)$ \\
\hline Somewhat satisfied (6-8) & $7(30.44 \%)$ & $5(21.74 \%)$ \\
\hline Unsatisfied (0-5) & $0(0 \%)$ & $0(0 \%)$ \\
\hline
\end{tabular}

Table 5 Distribution of frequencies for the outcome variables of the procedure $(n=23)$

\begin{tabular}{|l|l|l|}
\hline Result & $\boldsymbol{n}$ & $\%$ \\
\hline Reintervention & 3 & 13.0 \\
\hline Would do it again & 23 & 95.8 \\
\hline
\end{tabular}

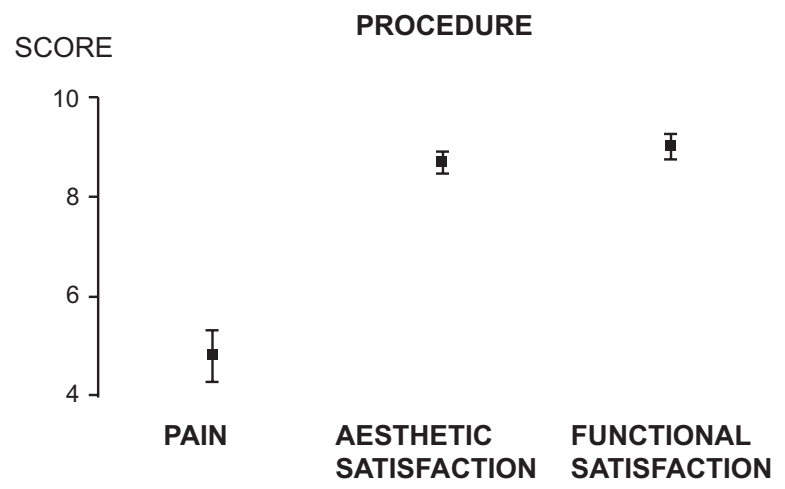

Fig. 4 Mean \pm standard error for the variables pain (during the procedure), aesthetics, and functional satisfaction (after the procedure).

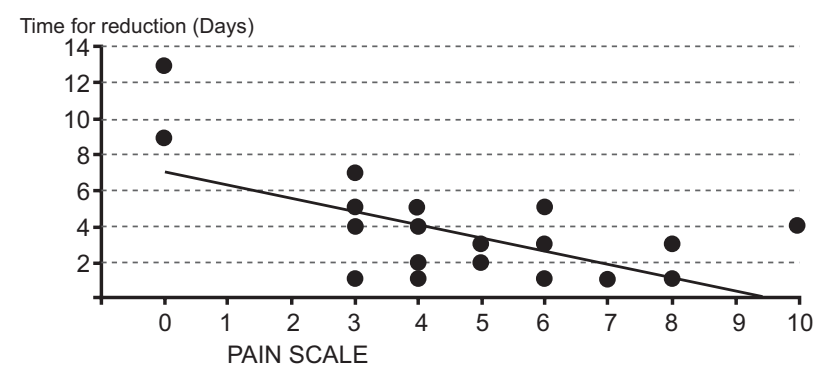

Fig. 5 Graph of correlation between the variables time for reduction and pain $(n=23)$.

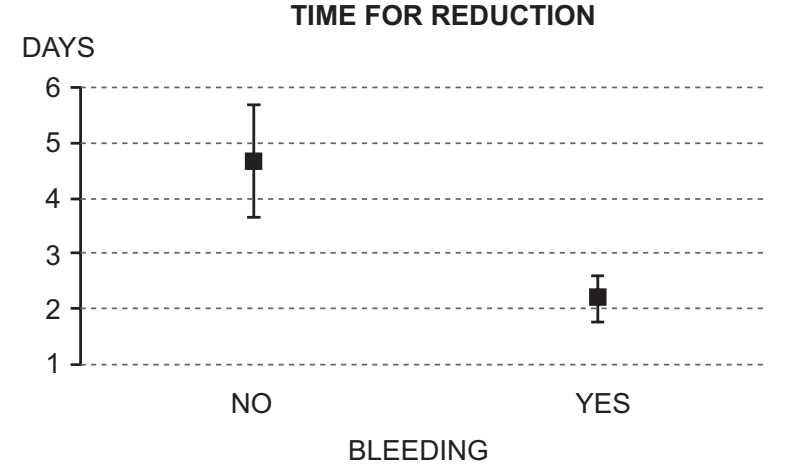

Fig. 6 Mean \pm standard error of the interval between the injury and fracture reduction for each group of patients $(n=24)$. 
Comparisons of the time to reduction between the groups of patients who showed malaise versus those who did not ( $p=0.957)$ and between the groups that showed lipothymia or not $(p=0.396)$ did not find statistically significant differences.

\section{Influence of the Physical Examination Findings on Admission in Functional and Aesthetic Satisfaction and Pain}

It was not possible to demonstrate a significant association $(p>0.093$ ) between the three variables (aesthetic satisfaction, function, and pain) and physical examination findings.

\section{Discussion}

Most patients exposed to the causes of facial trauma were young males, and most were because of automobile accidents, in addition to physical assault and trauma in sports, with an emphasis on football. Epidemiologic data from the study are consistent with those of Bakardjiev and Pechalova ${ }^{11}$ and Wulkan et $\mathrm{al}^{12}{ }^{12}$ highlighting the predominance of male subjects. Most facial trauma occurred over the weekend, especially on Sunday, which may reflect the greater exposure to risky activities mentioned above, in addition to the higher consumption of alcoholic beverages.

During the execution of the procedures in the 24 patients studied, we found that $12.5 \%$ (3/24) had lipothymia, one during infiltration of the anesthetic, resulting in the interruption of the procedure, and the other two at the end of the procedure, not interfering in the outcome. All of these patients recovered within a short period of time, requiring only postural repositioning, with elevation of the lower limbs to the plane of the trunk or placement of their heads between their legs. Thus, there was no complete loss of consciousness. We chose to classify patients as having "malaise" if they described a subjective feeling of malaise, without presenting physical signs of lipothymia such as sweating, pallor, or altered level of consciousness, totaling 8.3\% (2/24) patients. All recovered in a few minutes, with the same conservative measures adopted to lipothymia.

We found a deviated septum in $50 \%$ of patients, but only $20.8 \%$ complained of nasal obstruction. The predominating septal deviation was to the right (33\% of patients), in contrast to the literature data, which show a higher prevalence of septal deviation to the left, around 70 to $80 \% .{ }^{13}$ Most often it was not possible to exclude the presence of septal deviation prior to trauma. It was not possible to analyze the correlation between this anatomical substrate and functional complaints during evaluation in the emergency room, because clots and the edema may affect such results.

We observed a high level of satisfaction with the cosmetic and functional outcome after the procedure, noting $0 \%$ dissatisfaction in these questions. All patients reporting being somewhat satisfied and recognized aesthetic gain after the procedure. However, $13.04 \%$ of patients received an indication for reoperation. These data are in agreement with other studies. $^{14,15}$
Although no statistically significant differences were noted in relation to the time from trauma to nasal fracture reduction with aesthetic and functional end satisfaction, it is clear that delaying nasal fracture reduction under the conditions of study for at least 3 days after the traumatic event could be beneficial due to less pain and less bleeding, although bleeding, in all cases in which it occurred, was minor and transient. It is believed that this finding is due to the fact that patients are under less stress 3 days following the traumatic event, in addition to the partial recovery of edema and ecchymosis. In general, pain in the procedure was well tolerated with a low rate on a VAS ( $4.8 \pm 0.5$ of 10$)$. Similar results were obtained by Khwaja et al, who showed average pain scores of 3/10 in the group under local anesthesia and $2 / 10$ in the group undergoing general anesthesia, with aesthetic score at least $8 / 10$ in $51 \%$ of patients under local anesthesia and in $52 \%$ of patients group under general anesthesia 2 weeks after the procedure. $^{16}$

Additional studies are needed to better understand the factors influencing the evolution of nasal fracture and its impact on the health of individuals.

\section{Conclusion}

Most nasal fractures occurred in young males exposed to physical assaults, car accidents, and sports injuries. This study showed benefit in delaying nasal fracture reduction under local anesthesia to at least 3 days after the traumatic event to decrease pain and nasal bleeding after manipulation. The treatment under the conditions of this study was effective and safe both in functional and aesthetic recovery of the nose, without the use of expensive materials or financial resources.

\section{References}

1 Illum P, Kristensen S, Jørgensen K, Brahe Pedersen C. Role of fixation in the treatment of nasal fractures. Clin Otolaryngol Allied Sci 1983;8(3):191-195

2 Renner GJ. Management of nasal fractures. Otolaryngol Clin North Am 1991;24(1):195-213

3 Cook JA, McRae RD, Irving RM, Dowie LN. A randomized comparison of manipulation of the fractured nose under local and general anaesthesia. Clin Otolaryngol Allied Sci 1990;15(4): 343-346

4 Chadha NK, Repanos C, Carswell AJ. Local anaesthesia for manipulation of nasal fractures: systematic review. J Laryngol Otol 2009; 123(8):830-836

5 Cook JA, Murrant NJ, Evans K, Lavelle RJ. Manipulation of the fractured nose under local anaesthesia. Clin Otolaryngol Allied Sci 1992;17(4):337-340

6 Jones TM, Nandapalan V. Manipulation of the fractured nose: a comparison of local infiltration anaesthesia and topical local anaesthesia. Clin Otolaryngol Allied Sci 1999;24(5):443-446

7 Bailey BJ. Head and Neck Surgery-Otolaryngology. Vol. 1. Philadelphia: Lippincott; 2001

8 Murray JAM, Maran AGD. The treatment of nasal injuries by manipulation. J Laryngol Otol 1980;94(12):1405-1410 
9 Rajapakse Y, Courtney M, Bialostocki A, Duncan G, Morrissey G. Nasal fractures: a study comparing local and general anaesthesia techniques. ANZ J Surg 2003;73(6):396-399

10 Waldron J, Mitchell DB, Ford G. Reduction of fractured nasal bones; local versus general anaesthesia. Clin Otolaryngol Allied Sci 1989; 14(4):357-359

11 Bakardjiev A, Pechalova P. Maxillofacial fractures in Southern Bulgaria-a retrospective study of 1706 cases. J Craniomaxillofac Surg 2007;35(3):147-150

12 Wulkan M, Parreira JG Jr, Botter DA. Epidemiologia do Trauma Facial. Rev Assoc Med Bras 2005;51(5):290-295
13 Mocelin M. Septoplastias. In: Stamm AC, ed. Micro cirurgia naso sinusal. Rio de Janeiro: Revinter; 1995

14 Robinson JM. The fractured nose: late results of closed manipulation. N Z Med J 1984;97(755):296-297

15 Hung T, Chang W, Vlantis AC, Tong MC, van Hasselt CA. Patient satisfaction after closed reduction of nasal fractures. Arch Facial Plast Surg 2007;9(1):40-43

16 Khwaja S, Pahade AV, Luff D, Green MW, Green KM. Nasal fracture reduction: local versus general anaesthesia. Rhinology 2007; $45(1): 83-88$ 